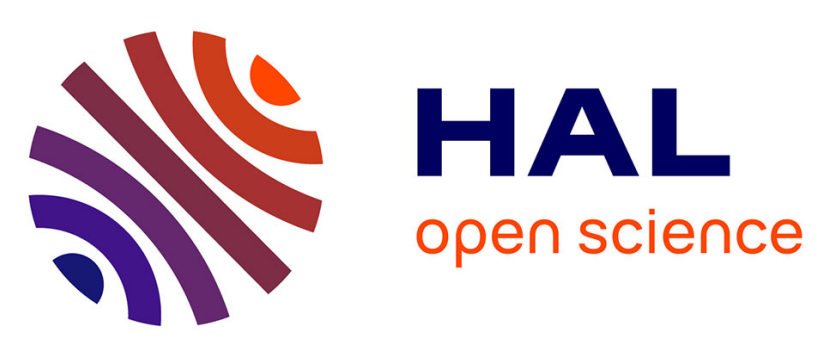

\title{
Falling on deaf ears: a qualitative study on clinical ethical committees in France
}

Catherine Dekeuwer, Brenda Bogaert, Nadja Eggert, Claire Harpet, Morgane Romero

\section{- To cite this version:}

Catherine Dekeuwer, Brenda Bogaert, Nadja Eggert, Claire Harpet, Morgane Romero. Falling on deaf ears: a qualitative study on clinical ethical committees in France. Medicine, Health Care and Philosophy, 2019, 22 (4), pp.515-529. 10.1007/s11019-019-09907-5 . hal-02950088

\section{HAL Id: hal-02950088 \\ https://univ-lyon3.hal.science/hal-02950088}

Submitted on 29 Sep 2020

HAL is a multi-disciplinary open access archive for the deposit and dissemination of scientific research documents, whether they are published or not. The documents may come from teaching and research institutions in France or abroad, or from public or private research centers.
L'archive ouverte pluridisciplinaire HAL, est destinée au dépôt et à la diffusion de documents scientifiques de niveau recherche, publiés ou non, émanant des établissements d'enseignement et de recherche français ou étrangers, des laboratoires publics ou privés. 
C. Dekeuwer, B. Bogaert, N. Eggert, C. Harpet, M. Romero, « Falling on deaf ears: a qualitative study on clinical ethical committees in France», Medicine, Health Care and Philosophy, 2019, 22 (4) :515-529

\section{Abstract}

The French medical context is characterized by institutionalization of the ethical reflection in health care facilities and an important disparity between spaces of ethical reflection. In theory, the healthcare professional may mobilise an arsenal of resources to help him in his ethical reflection. But what happens in practice? We conducted semi-structured interviews with 22 health-care professionals who did and did not have recourse to clinical ethical committees. We also implemented two focus groups with 18 professionals involved in various spaces of ethical reflection in order to let them debate about a better way to organize ethical reflection in their institutional contexts. The qualitative analysis allows to us to underline the coexistence of different conceptions of ethics among health care professionals. We also observed that the participants in our study shared the experience of ethically problematic situations as roadblocks in the process of communication and decision-making. We therefore report the factors which favour or inhibit the ethical course leading to the resolution or at the very least soothing of the situation at hand. Finally, we discuss methodological issues and underline the fact that while the patient is at the heart of the professional's ethical preoccupations, this does not imply that they are actors in decisions that concern them.

\section{Keywords}

Clinical ethical committee, France, qualitative research, institutionalization of ethics, interprofessional communication, doctor-patient communication

\section{Acknowledgments and Funding Information}

We wish to warmly thank the participants in this study as well as the students who contributed to a part of this study.

\section{INTRODUCTION}

Not much is known about clinical ethical committees (CEC) in France. A first study about French CECs was published in 1983 (Isambert), followed by a report (Le Mintier-Feuillet 1998) and by a comparison between CECs in France and in the United States (Mino 2002). Some regional or local experiences have been published, such as a survey of development of ethics in health care institutions that can be downloaded from the Espace Ethique Ile de France (Jolivet 2015), a testimony of the Bioethical Committee of Bordeaux (Daubech 2012) as well as research on the Centre of Medical Ethics of the Catholic University of Lille (Boitte et al. 2012). The integrative worldwide literature review about CECs (Rasoa et al. 2017) encompasses academic articles written in English between 2000 and 2016 but none were about the French situation. While international academic literature presents several methodologies to support ethical reflection in CECs (Steinkamp and Gordijn 2003; Fox 2010; Magelssen et al. 2016), there is little data or reflection about a suitable methodology for the French context.

In France, ethical committees started developing in 1980. The National Ethics Advisory Committee (Comité Consultatif National d'Ethique or CCNE) was created in 1983 by decree 
in order to "to give advice on the ethical problems raised by the progress of knowledge in the fields of biology, medicine and health and to publish recommendations on these topics" (2004 Law relative to Bioethics). The CCNE is an independent, consultative authority with no decision-making powers. Ethical questions raised by the CCNE include questions which cause considerable societal debate, such as end of life, but can also come by request from its members or directly from citizens. In 1988 the Advisory Committee for the Protection of Persons in Biomedical Research (Comité Consultatif de Protection des Personnes dans la Recherche Biomédicale or CCPPRB) was created by law (Law relative to the protection of persons in biomedical research) in order to examine research protocols on human subjects. As before 1988 each French university hospital had its own research committee dedicated to research, the creation of the CCPPRBs, and since 2016 the CPP (Comite de Protection des Personnes), led to a modification in the missions of these committees, orienting them more directly toward clinical ethics instead of examining research protocols on human subjects (Mino 2002).

A March $4^{\text {th }} 2002$ law relative to the rights of the sick and the quality of the health system created the obligation for each health care institution to implement a "reflection on the ethical issues raised by the reception of patients and the medical care". A certification procedure has been in place since 2010 (Haute Autorité de la Santé 2010) in order to help institutions implement ethical reflection, to develop actions and recommendations for good practices and to promote the respect of patients' rights. An additional certification procedure has been in place since April 2013 to evaluate the ethical aspects of medical care. French health professionals are now obligated to organise, implement and evaluate ethical reflection within their institutions, and this obligation often takes the form of an ethical committee, which includes responding to requests for therapeutic decision support. Today, one in three public hospitals in France has its own CEC (FHF 2016).

In order to complement ethical reflection at the individual hospital level, Regional Ethical Reflection Spaces (Espace de Réflexion Ethique Régional or ERER) were created in connection with the 2004 Law in order to provide a space for training, documentation, and exchanges on ethical issues in the field of health. There also exist regional and interregional observatories of ethical practices. These spaces participate in the organization of public debates in order to promote citizen information and consultation on bioethics issues. In 2018, for instance, the ERERs organized a set of events in each French region to promote citizen participation and public discussion about bioethical problems before re-examination of the laws at the national level under the supervision of the CCNE.

In order to summarise the French context, we may use the following distinctions, based on Mino's (2002) and Jolivet (2015) observations and on our inquiry. To begin with, research committees (CCPPRB and CPP) remain separated from clinical ethical committees (CECs). France does not recognize the profession of the ethicist and participation in ethical committees remains both voluntary and unpaid. In healthcare facilities, CECs show a great diversity in both aim and methodology. "Ethical Committees" on the one hand, are often created and/or promoted by hospital management (often following the HAS's requirement for certification procedure) with a strong representation of university physicians, one or several representatives of the hospital administration and some outside members (philosophers or representatives of cults for instance). On the other hand, "groups of ethical reflection", are created by a personal initiative (a physician or a nursing manager for instance), which tend to include less physicians and claims to be independent of any institutional procedure. After the institutionalization of the 
ethical reflection in health care facilities created by the law and the HAS certification, some problems were identified, such as the confusion between compliance with law vs with ethics or the tendency to delegate ethical reflection to a committee instead of developing personal reflection (Dekeuwer et al. 2011). Groups of ethical reflection and formal ethical committees are also different in scope. While the ethical committees work at the institutional level (the hospital or the university hospital, which encompasses several hospitals), a group of ethical reflection involves a team or a few professionals from the same specialty (gerontology for instance) dealing with "their" ethical problems. In addition, there are also innovative models being created. For instance, based on the work of Mark Siegler at the Mc Lean Centre for Clinical Medical Ethics, a "Clinical Ethics Centre" was developed at the Cochin Hospital in Paris. Unlike other groups of ethical reflection and ethical committees, patients, families as well as healthcare providers can request review by the committee and at any time of the day or night. Interviews with major stakeholders, including patients and proxies, discussions, case conferences and follow up are parts of the methodology (Fournier et al. 2015).

The French context is characterized by institutionalization of the ethical reflection in health care facilities and an important disparity between spaces of ethical reflection. This diversity underlines a relatively free operating system that differs from one place to another (for instance from one hospital to another). In theory, the healthcare professional may mobilise an arsenal of resources to help him in his ethical reflection. But what happens in practice? We conducted 22 semi-structured interviews with health care professionals who did or did not have experienced the help of a CEC (for the fluidity of reading, we will use "CEC" to refer to Clinical Ethics Centre, ethical committee and group of ethical reflection) in the process of dealing with a difficult situation. We also organized two focus groups with professionals involved in the development of CECs. Our findings shed light on three main questions: what are the representations of ethics put forward by the professionals participating or not participating in CECs? Is there a gap between the organization of ethical reflection and the needs of health care professionals not participating in CECs? And finally, what is the place of the patient when professionals and ethical committees are confronting ethical issues?

\section{METHODOLOGY}

The research was developed and conducted by a multidisciplinary and international team: two researchers, French and Swiss, are philosophers and ethicists both involved in academic missions and members of hospital ethical committees in their countries. The other two researchers are members of the University of Lyon III Research Chair in Patient Centred Care. One is an anthropologist and the other a sociologist and a philosopher.

We did two parallel studies. We conducted semi-structured interviews with twenty-two healthcare professionals. The participants had different professions (physician, nurse, social worker, genetic counsellor, psychologist, health care manager), and worked in different medical specialties (Prenatal Diagnosis, Critical Care, Geriatrics, Genetics, Addiction medicine, Haematology). Among the physicians, some were also researchers and some have management positions. They worked in university hospitals, private establishments or had an independent status. During the interview, professionals were asked to describe a difficult situation they faced. We intentionally left open the definition of ethics so as to not influence their viewpoints and in order to have a better understanding of what is, for them, an ethical issue. We asked them 
how they dealt with the problem, if they had recourse to any ethical committee or group of ethical reflection and what could be improved to deal with ethical issues. As one of the researchers was responsible for a Master's course aimed at teaching qualitative methodology in applied ethics, students participated in the elaboration of the interview guide. They were also invited to conduct two interviews two by two and transcribed the interviews verbatim. The professor monitored the interview transcriptions and worked with the students to analyse the results. All the students agreed to the possibility that the verbatim transcription could be used for further research. The four researchers went back to the verbatim interviews in order to further analyse and compare the results with the second study.

\section{Table 1: population}

\begin{tabular}{|l|l|}
\hline Gender & 8 men and 14 women \\
\hline Age & 30-40 years: 9 persons \\
& 40-50 years: 5 persons \\
& 50 years and more: 8 persons \\
\hline Profession & Doctors: 12 (4 researchers) \\
& Health manager: 2 \\
& Nurse: 5 \\
& Social worker: 1 \\
& Psychologist: 1 \\
& Genetic counselor: 1 \\
\hline Department of exercise & Hospital administration \\
& Addictology \\
& Hematology \\
& Critical Care \\
& Genetics \\
& Prenatal Diagnosis \\
& Elderly Care \\
& Palliative care \\
& Geriatrics \\
& Nurse school \\
\hline Education in humanities (including ethics) & None: 11 \\
& Awareness: 7 \\
& Degree level: 4 \\
\hline
\end{tabular}

We also implemented two focus groups with 18 professionals in order to let them debate about a better way to organize ethical reflection in their institutional contexts. We organized the debates during an international scientific conference at the Faculty of Philosophy in order to provide a safe space for the debates. The conference aimed to better understand the methodology used in the ethical committees, clinical ethics centres, or ethical groups of reflection. During the first part of the day, researchers presented different methodologies used in different contexts and countries. The students involved in the interviews were also given the opportunity to present their results. The second part of the conference was dedicated to the focus groups with the professionals in small groups. 
We chose the methodology of the focus group because it was a good way to analyse how our research question is understood and discussed among stakeholders. According to Kidd and Parshall (2000), people do not say the same things or in the same way in a group or individually, in a focus group or in other settings. The participants relate their experiences and reactions among presumed peers with whom they likely share some common frame of reference. Furthermore, a focus group generates debates among participants and allows researchers to study how people discuss by negotiating, confronting positions or helping each other. The focus group methodology allowed us to study shared representations and common experiences and to explore the interactions between participants.

We chose a more select group of people implicated in the creation, the facilitation or the development of ethical reflection in different private and public hospitals (Regional Ethical Spaces, institutional ethical committees, the Clinical Ethics Centre and groups of ethical reflection) for this part of the methodology. We tried to balance the two focus groups with the inclusion of people from several educational backgrounds (psychologists, pharmacists, physicians, philosophers and nurses), working in different structures and specialties (palliative care, psychiatry, emergency, reproductive medicine and neonatology) and job titles (consultant, teacher, researcher, health-care provider, manager). One of the participants has a central position in the organizational hierarchy. As they were also involved in different types of ethical spaces, we were attentive to distribute them equally in each group. None of them was working in the same service but some of them knew each other through parallel missions related to ethics. During the analysis, we realized that it was impossible to class the participants, for instance according to their job titles. Each of them has an original history encompassing missions dedicated to health care and developing critical reflection. For instance, one doctor did a Master in anthropology and was a co-creator of a group for ethical reflection in her hospital. One $\mathrm{PhD}$ philosophy student also completed an internship in a palliative care service and was working in the Regional Ethical Space. The pharmacist was also a researcher and the promotor over ten years of "café philo", a grassroots forum for philosophical discussion and member of an institutional ethical committee. We also invited two "student intruders" who provided an outsider perspective. The student was not directly involved in ethics committees unlike the other participants. One was working on his Master research project on hospital architecture; the other was an advanced mid-wife student. We included these outsiders to provide a "fresh" perspective from those not fully integrated into the daily work of clinical service, who are between theory and practice, which might be able to question what those with extensive knowledge may take for granted.

The focus groups lasted one hour and a half and responded to two principal questions moderated by a researcher (one philosopher and one anthropologist). In order to avoid methodological bias, each researcher asked the same questions using the exact same words. The researchers did not directly intervene in the debate, except to ask follow-up questions where clarifications were needed. At the end of the discussion, the participants were invited to write on an individual post-it three key words summarizing the discussion. This was both in order to give them the opportunity to express private thoughts about the debates and to give us some orientation for the thematic analysis. A facilitator (one philosopher and one sociologist/philosopher) was also present but did not participate directly in the discussion. They presented a short summary postdiscussion in order to guide a final thirty minute debate between the two groups.

The discussion was focused on two principal questions: 
Question 1: In your practice, you have probably been confronted, either directly or indirectly, with a situation which seemed to you ethically problematic. Can one of you tell us about how this problem was questioned and eventually resolved?

Question 2: What would be the 'ideal space' to discuss ethical questions in the hospital?

The interviews and focus groups transcriptions were analysed by means of qualitative tools (Bertrand et al. 1992, Markova 2003, Kaufmann 2007, Baribeau 2009). Each researcher read the transcriptions. We then proceeded with a thematic analysis. For the focus groups, we also conducted a conversational analysis that included the time each person spoke, in what context and in what order they responded to the researcher's questions. We also analysed the function of the researchers' interventions based on the distinction made by Blanchet (1982): functions of production (opening or follow-up for instance), confirmation (reformulation or corroboration) and orientation (refocusing on the theme for example). We took into account the group dynamic, considering successively the place of the individuals in the group and the impact of the group dynamic on the individuals. The thematic analysis was based on an iterative and reflexive method. The researchers independently examined the transcriptions and generated their own themes. We agreed together to a final set of themes and questions derived from the data. We also identified key quotations from participants, all the while taking into consideration their context. After having identified these themes, we recontextualised the data in order to have a better understanding of the representations, the issues the participants have to face, and their reasoning and moral assessments. For example, we identified the theme of the place of the patient in ethical reflection. We gathered the occurrence of this theme in the focus group and in the interviews, identified at what moment it was discussed, in which step of the reflection of the participant the patient comes into view, which emotions are expressed when they speak about the patient, and if there was explicit or implicit moral assessment about the situations evoked.

All the participants were informed of the aim of the research by written explanation coming with the invitation to take part to the study. They agreed to the recording of the interviews and focus groups, making the transcription and anonymization of the data and then sharing the transcriptions between the researchers of the team. The necessary declarations to the National Commission for Informatics and Liberty (Commission Nationale de l'Informatique et des Libertés or CNIL) were made. Ten months later, we invited the participants to a presentation and discussion of the results.

\section{RESULTS}

\section{What do "ethic" and "ethical" mean? Results from the interviewee's analysis}

The health care professionals we interviewed individually (see Table 1) were not directly involved the creation and/or involvement in ethical committees. Only six out of 22 health care professionals had a personal experience of requesting a CEC: two had recourse to the institutional ethical committee of their hospital and four had experiences with groups of ethical reflection. Other resources have been experimented with including a colleague's referral, a palliative care department and the Pluridisciplinary Committee for Prenatal Diagnosis (Comité 
Pluridisciplinaire de Diagnostic Prénatal) ${ }^{1}$. The CCNE and the CPP were also mentioned during the interviews, although they were not solicited. The data shows that for the persons interviewed, there is not direct and generalizable correlation between the profession or the department of exercise and the request of a CEC.

Our analysis suggests a global lack of knowledge of the ethical resources a French professional can mobilize. Some health care professionals attributed the goals and functions of some committees (for instance the CPP) to other ones (for instance the institutional committee of their hospital). Some of the motives to not solicit an institutional committee are also related to a lack of knowledge. One nurse expressed it as the following: "how can you call an institution when you don't really know how it works?" Furthermore, some persons who did not have any personal experience of CECs consider ethical committees as inappropriate, being "too far from the reality of patients". The lack of knowledge leads indeed to a set of prejudices and miscomprehensions.

Some of the persons we interviewed (who did and who did not request the help of a CEC) associated CECs with a special ethical competency, an expertise only useful for (very) difficult cases. In that view, an ethical committee is considered as giving a formal and fixed answer and not as helping health care professionals to progress in their reflections and decision making. However, institutional ethical committees are not considered by all the participants as the best place to tackle with ethical issues, mainly because it comes down to the healthcare team to handle the situation. In other words, an ethical resolution cannot come from outside. As her institution decides to dedicate some specific time, in summer, to ethical reflection, a nurse for instance considers that "it makes us good to set down things" and observes that little things from daily life have changed. In her view, this space of ethical reflection that mobilizes professionals who are working together is a good way to handle difficult situations in her service.

In order to justify that they do not solicit a CEC, the professionals we interviewed refer to several kinds of motives. One of them is related to the organization of the work: the lack of time. In France, ethical reflection does not appear in the repository of professional tasks. It is done on a voluntary basis. The fear of appearing incompetent was also mentioned and appears to be linked to the role some professionals have to assume as decision-makers as well as to the way they define "ethics". This fear takes on a meaning in the specific representation of ethics by decision makers.

Indeed in the course of the interviews, almost half of the participants stated spontaneously a definition of ethics. On the one hand, ethics was related to a specific professional attitude that implies the presence and development of specific virtues. On the other hand, ethics is related to a process of global analysis that considers all possible points of views. These representations are related to the specificities of the professions of the participants, but their specialties (geriatrics or genetics for instance) do not seem to influence their conception of ethics. More precisely, our results suggest that these representations are related to the position of the decision-maker.

\footnotetext{
${ }^{1}$ CPDPNs are committees made up of physicians and aimed in particular at examining the conformity of the couple's requests of abortion for medical motives with the law.
} 
For the physicians and the psychologist interviewed, helping people implies specific virtues, such as generosity, sincerity and the ability to question oneself. For the doctors, being a physician implies also having a special kind of virtue related to the ability to take the best decision. Exercising and improving this virtue is expressed by these words: "do I propose the best solution for my patient?" or "can I do better than what I decided to do?" Ethics is thus referred to a professional challenge and the meaning of "virtue" is excellence. The representation of the doctor as the one who has to take and carry the weight of the decision is shared by the interviewees. A nurse takes the example of the French movie, Hippocrates (Lilti 2014), in a case about taking an end of life decision. She explains: "the nurse will not act because she is the nurse. She acts only under the command of the doctor. Thus she may well have the needle in her hand, it is not her that acts".

Table 2: Representation of ethics

\begin{tabular}{|l|l|}
\hline Perspective 1 & Perspective 2 \\
\hline Physicians, psychologists & Nurses, care managers \\
\hline \multicolumn{1}{|c|}{ A specific professional attitude } & $\begin{array}{l}\text { An ability to conduct an } \\
\text { analysis that encompasses } \\
\text { exhaustively all the pertinent } \\
\text { penerosity }\end{array}$ \\
$\begin{array}{l}\text { Sincerity } \\
\text { Excellence } \\
\text { Ability to question oneself } \\
\text { Ability to take the best decision (doctors) } \\
\text { Psychological strength }\end{array}$ & $\begin{array}{l}\text { That implies : } \\
\text { Approach adapted to each unique } \\
\text { situation } \\
\text { Personal and collective reflection }\end{array}$ \\
\hline \multicolumn{2}{|c|}{ The patient at the heart of ethical concern but his exact position and role are } \\
\hline
\end{tabular}

With the exception of one person who has a $\mathrm{PhD}$ in philosophy, none of the doctors we interviewed had an education in ethics or social sciences. The younger generation had humanities classes during the first academic year or training but does not seem to consider that it is useful: the courses are not adapted to the practice. Moreover, some of the doctors, more or less advanced in their career, explained that there is no need of theoretical formation because ethics is a matter of "psychological strength" and is learned by mentoring ("compagnonnage") when "you have the chance to meet a beacon with whom practical medicine is learned". There is a sense therefore that ethics has to be learned on the ward.

The second perspective of ethics is developed by nurses and care managers. According to that perspective, ethics refers to the ability to conduct an analysis that encompasses exhaustively all the pertinent points of view. The approach must be both global and adapted to each unique situation, as underlined by the following questions: What is the cultural environment? Which are the legal obligations? How does the medical team function? How does the patient interact with professionals and with his or her family? What does scientific literature say about the pathology? Are there published guidelines or good practices? How should we adapt them to the 
patient? What is the story of that patient? What is my personal and professional story and how does that impact the situation? As summarised by a nurse who became an ethics teacher in a nursing school: "we have to discuss with all the persons that surround the patient, his or her proxies as well as care professionals, and to keep in mind administrative and equity issues." According to this perspective, ethical reflection is both personal and collective and worthy only for one situation at one moment in time. As four nurses and health care managers out of seven completed their initial formation with a specific education in ethics, we wondered if this representation of ethics was inspired by this education. It is worth noticing that those who did not have training in ethics share the same conception of what counts for ethical reflection: education in ethics is thus not the only factor explaining this shared conception.

It is worth noticing that both during the interviews and the focus groups, a formal definition of ethics appears repeatedly: doing the best for the patient. For instance, considering situations of end of life in Charcot disease, one doctor explained that she complies with the wishes of each patient. There is nothing like a common decision or partnership. This doctor's explanation allows us to go further. She explained that, except for requests that are against the law, "anyway, the patient makes the decision". However, she also said that "we make the decision". She explained indeed that, for end-life decisions, the team listens to the patient as well as his or her proxy wishes. Nevertheless, the team presents the decision (that follows these wishes in her example) as their own, in order to carry the weight of the decision. She explains: "we cannot ask a family to say "let my dad die", it's too heavy. So we explain to them that we make the decision, even if in reality they are involved". In most situations described by the participants to our study, the border between benevolence and paternalism is blurred. Most of the time, from a declarative point of view, the patient is thus at the heart of ethical concerns. Nonetheless, the way participants relate the difficult situations they dealt with or explain how decisions are taken shows that the patients do not participate and/or contribute to the decision. Only three definitions of ethics (from a psychologist, a public health professor and a nurse) focused on the patient's point of view. Even the representation of ethics as the ability to conduct an analysis that encompasses exhaustively all the pertinent points of views does not underline the importance of the patient's active participation in ethical reflection or decisions. The place of the patient remained ambiguous both in our focus group discussions and in our interviews. When participants in our study are considering in an abstract manner or in general manner the patient-physician or patient-caregiver relationship, the word "partnership" is often used. It refers to the fact that a common decision, based on dialogue is made. However, the descriptions of the way difficult situations were dealt with reveal that they made the better decision for the patient. Overall, the idea of a "shared decision" (between professionals or with the patient) is absent from our study, a factor which will be elaborated in the discussion section.

\section{Factors that inhibit or promote the ethical course. Results from the Focus Groups}

The focus groups allowed us to further analyse the situations that the participants involved in CECs considered as problematic from an ethical point of view. It appears that the term "ethics" refers both to specific bioethical issues (end of life, abortion for clinical motives, the decision to stop treatment, excessive and futile therapy for instance) and to the way these issues are dealt with by a team or a CEC. In other words, ethics refers both to the content of an issue or to the 
procedures by which a solution is eventually reached. Moreover, the "moral distress" of professionals is related to the way a bioethical issue is dealt with by a healthcare team or a CEC. All the participants chose to exemplify the "ethically problematic situations" by situations of deadlock. Disagreements or conflicts between members of a clinical team or an ethical committee and conflicts with the patient or family are the matrix of moral distress and ethical reflection. The phrases used are "to turn in circles", "we will not manage", "the team doesn't agree", "it's the only case where we could not agree".

To pursue our analysis, we studied in detail the situations described by participants as roadblocks. We observed that the moral distress remained unresolved or was soothed depending on the ways persons enter into the relationship and were able to interact within that relationship. The way in which participants described how they dealt with ethical issues, their decision making, and ideal ethical places lets us see the inhibiting factors and enabling factors to resolution or at the very least soothing of the situation at hand. We call this process of resolution or soothing of the situation "ethical course" because our results show that the determination of a decision, a position or a reflection as "ethical" or "not ethical" depends on this course. Tables 2 and 3 summarize factors which inhibit or promote ethical decision making.

Table 3: Factors which inhibit the ethical course

\begin{tabular}{|l|l|}
\hline Factors which inhibit ethical reflection & Problem \\
\hline Lack of a relationship & $\begin{array}{l}\text { Relationship } \\
\text { difficulties }\end{array}$ \\
\hline Fear & $\begin{array}{l}\text { Procedures of } \\
\text { discussion and } \\
\text { decision }\end{array}$ \\
\hline Frontal relationship or manipulation & $\begin{array}{l}\text { Hospital } \\
\text { organization }\end{array}$ \\
\hline The lack of justification for decisions and opinions & \\
\hline A waidity to present the case which "astound" & \\
\hline The place of healthcare providers in relation to others & \\
\hline Healthcare fragmentation which makes the meaning disappear \\
Ethical reflections carried mainly by doctors rather than the whole \\
healthcare team
\end{tabular}

As summarized by Table 3, there are several factors which inhibit the ethical course. These can be divided roughly into three main domains: relationship difficulties between healthcare providers and/or the patients, procedures of discussion and decision, and hospital organization.

Firstly, the absence of an encounter between the healthcare team and between healthcare providers and patient are important factors which inhibit the ethical course. Some health care professionals report having experienced some "violence" and/or "hostility" from the patient and/or his or her family that does not allow a relationship or encounter. A doctor for instance described the attitude of a patient as "very aggressive" because she did not want to meet him. The impossibility to enter in relationship also characterizes some professional interactions. Not 
to be listened to by another professional is mentioned, and may be at least partially explained by this testimony: "we never learn how to speak with other professionals". In the opinion of some participants, the education of healthcare professionals should include some skills that enable them to speak with each other.

Secondly, the feeling of fear of the patient and/or other healthcare providers is also expressed: the fear that the patient will "put his nose" in CECs for instance, or that "the demands of patients which can go in all directions". Thirdly, the frontal relationship with the patient also inhibits the course of ethical reflection or decision. When the focus group participants talked about difficulties with some patients, they used passive verbs and visualisations that place the patient "in front of" health care professionals. A doctor justified this by their academic medical education which objectives the patient. Some relationships were also described as "manipulation" of the patient and/or the family member. "It's practically treachery" said a doctor about the way she acted with a patient. On the other side, some patient's requests do violence to doctors. One of them talked about the "urgent side of the request" of some patients. In her words, the expression "to make the patient happy" means that she feels like an object, at the best a provider of a service.

In one focus group, the situation of the roadblock was also related to silence: the team is confronted with a situation that is too painful to be discussed. One doctor suggests indeed reflecting on the situation of a couple who asked if it were possible to undergo artificial insemination to have a child. The man had a cancer with a short life expectancy, and the doctor explains how much the medical team was divided. Some insisted on the necessity to respect the autonomy of the patient, others on the benevolence for the child, who would be born an orphan. He also explains that this situation was disputed during two ethical committee sessions, leading also to disagreement between the members of the committee. In the course of the focus group discussion, it appears that the ethical issue was foremost about the way the decision has been taken in the team (and not about the couple's request). One member of the team imposed her point of view and the doctor finally expresses his worry: what will happen when another couple will come with a similar request? As the team is not able to exchange views about this painful experience, how could they manage to make an acceptable decision from an ethical point of view? The focus groups discussions enable the doctor to conclude: "The problem is not the decision we made, but the profound discontentment with the process of decision making that we will experience again in the same way."

The way ethical reflection is conducted or the way a decision is taken may indeed inhibit the ethical course (the second problem identified in the Table 3). The lack of justification for decisions and opinions inhibits the ethical course. Where there are no "because" and no explanation, when no arguments feed the reflection, moral distress takes hold. The ethical course may also be inhibited by some ways of presenting the problem, especially in the ethical committee. As the participants of focus groups underline, some presentations are bewildering and paralyze ethical reflection. "Rigidity" from all possible participants is a third difficulty. Inflexible attitudes, positions by "principle" and religious convictions are all enemies of the ethical reflection that could lead to a resolution or soothing of the situation. In the example of the couple who asked if it were possible to undergo artificial insemination to have a child for instance, one important point of the team discussion was the fear that this decision, taken for this couple, becomes a kind of "law" that would constrain the team to have the same answer for all the couples in similar situations. More generally, the persons who participated to our 
research were divided about the idea that an ethical solution is each time unique and singular for each healthcare team or ethical committee and at that moment in time. They debated the question: "is that a source of richness or a limitation for ethical reflection?" These results underline the importance of a reflection about methodology to favour ethical reflection.

The final theme identified was the way the hospital is organized and the teams managed, as well as some professional habits may also impact the ethical course. According to the participants of the focus groups, the division of healthcare tasks has made its meaning disappear. Some management practices break the care delivery up, dividing the process in parcels, so that the professionals lose the meaning of the intervention. In addition, the introduction of the patient into an ethics dispute adds an additional burden to the daily work of the healthcare provider team. According to one doctor from the focus group discussion, "we are used to following the medical file on the patient. Medical ethics cases overfill our already full workload and ask us to pass time with the patient in a relational quality". While the patient and/or the family is the source, the heart, of the ethical problem, he or she is also a barrier to daily work and makes more demands on an already overworked healthcare team. The inclusion of the patient and/or family into the encounter demands more time which healthcare providers are reluctant to provide (or simply cannot provide) in the face of increasing workplace demands at the hospital.

The place for healthcare providers between each other is also an important topic, and the participants expressed a feeling of unease. One member of a mobile palliative care unit asked: "is it really ethical that we intervene only on request of a physician?" She suggested that the patient, his or her family, even a nurse should also be allowed to ask for the help of this unit. A psychiatrist wonders if the role her colleagues bring her to play is the best. She explains also that "the specialist of reanimation would like that we know what the family wants. But it is not exactly our place". Some members of ethical committees underline the hierarchical effects that occurs in some sessions. During the focus groups, we observed that the participants mixed themselves around the table. The desire to bring an interactive discussion to the group was evident. Each person would listen carefully to each other and nobody interrupted the speakers. We noticed that doctors were the first to respond to animator's questions and that the participants tended to adopt their professional postures. These observations lead to the hypothesis that the focus group replays the communication processes and the habitual hierarchies of professionals. One physician was aware of this difficulty: "Just a remark on speech. We are used to a speech which is codified, that is hierarchical, in our ways of working. There is the speech of the doctor, which has a certain knowledge. And that speaks more easily. The nurse's speech, there is a place for it also... and this speech...there is a distribution, let's say, natural, of speech in our system, because we work in that system. And to redistribute these communication cards, we must liberate ourselves from this... and anyway, we are "preprogrammed", in quotation marks, in our way of speaking up, in how much we can speak, and to allow speech from a student, for example. And it's true that it demands... I think it's an important roadblock, and it requires us to have a place where we can put our professional costumes in the locker-room before entering into a different kind of speech in the interior of ethical committees." Obviously, the space of the focus group did not allow us to redistribute these communication cards.

The consideration of the hierarchical habits of healthcare professionals as well as the characteristics of ethical reflection lead them to the idea that ethical spaces of reflection should start from the ground. Some of the participants in our inquiry denounced the mirage of the 
ethical "alibi" or an all "miracle solution" coming from ethical committees when the healthcare team is "turning in circles". On the contrary, focus group participants suggested that the ethical course should be led by the healthcare team and not by external sources or just by doctors. For instance, one promoter of a group of ethical reflection, herself a physician, explained that doctors should not have the leadership of such spaces. According to her, it is the most assured manner to fail to engage in a collective ethical reflection. She explained that the group of ethical reflection was created only when all the team (including the caregivers) agreed to carry the project. "If there is a team who wants to gather together in a common desire and if there is a desire to put things into perspective, in fact, to take some time to think outside of the technical act... it works better as if it is carried out by an external team."

All these factors we have identified may influence each other: communication difficulties for instance are often generated or amplified by the organization of the ethical structure. The medical objectification of the patient may also induce a poor justification of a medical decision. It is worth noticing that all these factors contribute to preventing the persons concerned to develop a relationship in which all participants are considered as subjects able to express and justify their opinion about that situation and deserving to be listened to. The space provided for ethical reflection, which is supposed to be an open, free space to discuss the ethical situation at hand becomes rather a one-way dialogue, or several dialogues which cross and do not meet together.

Table 4: Factors which favour the ethical course

\begin{tabular}{|l|c|}
\hline Factors which favour the ethical course & Solution \\
\hline Collective intelligence & $\begin{array}{c}\text { Quality of } \\
\text { Relationships }\end{array}$ \\
\hline Speaking in confidence & $\begin{array}{c}\text { Procedures of } \\
\text { discussion and } \\
\text { decision }\end{array}$ \\
\hline Recognition of the legitimacy of everyone concerned & $\begin{array}{c}\text { Spaces and } \\
\text { temporalities } \\
\text { for exchange }\end{array}$ \\
\hline Explity to take distance & $\begin{array}{l}\text { Feeling free to reflect } \\
\text { Time to exchange } \text { a posteriori }\end{array}$ \\
\hline Informal but dedicated temporalities and spaces & \\
\hline Support from the institution &
\end{tabular}

If the participants in the focus groups do not describe an ideal space for ethical reflection by drawing a structured picture, the debates show some conditions that favour the resolution or soothing of complex situations. In the interviews, professionals express some wishes and ideas aimed at improving the way they can deal with ethical issues. These themes are summarised in Table 4 above and can be roughly be divided into three main results regarding the quality of relationship, the procedures of discussion and decision and the spaces and temporalities for exchange.

Firstly, in the focus groups, it was seen that the collective enables us a real path forward in ethical reflection. The opinion that "we think a better way as a team/group" is widely shared by the healthcare professionals we met. What is the virtue of the collective? First, it functions as 
reassurance. For instance, a colleague, a group, an ethical committee confirms that the professional did his/her best or chose the best option. Moreover, he or she is no more alone, even if he or she is responsible for the decision. One participant, a nurse, insists on the importance of being able "to pass the baton" when the situation is too difficult.

Furthermore, all those implicated in difficult situations, including the patient, should speak in confidence. The recognition of the legitimacy of everyone involved (including the patient) to participate to the reflection is considered as favouring the ethical course. One nurse and philosopher developed the importance of this attitude: "speaking at the height of the face", the opposite of looking down on someone. This opinion is based on her experiences in participating in groups of ethical reflection and in assisting healthcare teams in difficult situations, as well as on the consideration (shared by several participants of the focus groups) that everybody, as a moral subject, has the same legitimacy in participate in moral debates.

A second result is related to the way the ethical reflection is conducted as well as the manner a decision is taken. One participant insists on the importance to feel free to think and to have this or that opinion. These debates should include two steps that favour an ethical resolution. First, exploring difficulties, going into depth about arguments, questioning aimed at a better comprehension of the problem. Secondly, confrontation and debate are necessary. The following attitudes are positively assessed: take a step to the side, take a step back, and letting doubt and reflexivity come. Even personal introspection seems to be useful, as one's personal life may affect professional attitudes.

Finally, according to respondents from our study, in addition to its inherent ethical value, this way to handle difficult situations has a positive effect on the well-being of the team. They share the opinion that time dedicated to ethical reflection on a posteriori situation should be promoted. Several persons who participate in ethical groups of reflection experienced these spaces for exchange without any decision having to be taken.

Thinking as a group and in confidence implies taking some time apart in specific conditions. Some participants explain that a calm place "where the telephones do not ring" favours ethical reflection. From their point of view, informal places and times should be reserved to ethical reflection. The times of shift changes, when a healthcare team succeeds the former team or some specific meetings that give rhythm to the work of a department, are not appropriate spaces for ethical reflection: the lack of time and medical issues take up all time and space. More generally, debates on the organization of work and workplace could be part of ethical reflection, since it influences the ways professionals as well as the patient develop relationships with the healthcare team. In addition, the focus group discussions open on considerations about education. The participants consider that a formation including ethical theories (the study of Beauchamp and Childress principlism for example) is not as useful as the promotion of a culture of dialogue, of reflexive abilities, of ethical sensibility. This conception of education needs to confirm to their conception of ethics as a reflexive activity, which is very close to philosophical activity.

Empirical data reveals therefore a strong agreement between healthcare professionals who had some experience in groups of ethical reflection or ethical committees. The ethical course that allows a resolution or a soothing of roadblock situations encompasses dialogue with all the stakeholders and reflexivity. In their perspective, getting help from the institution is necessary, but the path should start from the ground. This quotation summarizes the perspective of 
healthcare professional we met: "when professionals can speak freely in teams, they have everything they need to find solutions." This opinion has some consequences on the role of ethical committees. No ethical solution may indeed come "from outside", but ethical committees could help teams to reflect by themselves in order to find their own solutions.

\section{DISCUSSION}

\section{The need for more methodological reflection for CECs}

As suggested by our study, healthcare professionals do not share the same representation of ethics, which refers to the excellence of a professional, to the characteristics of a special kind of analysis, or to a specific way to solve conflicts. This means that they may communicate different things when speaking about the same thing: in effect turning a deaf ear to one another. As we were wondering if the representations (and their translations into practice) of the health care professionals involved in the creation, the facilitation, or the development of ethical reflection meet the needs of health care professionals that are not implicated in such ways in CECs, the importance of the implementation of and the communication about methodology became more and more obvious.

No clues in the participant debates indicate that any space of ethical reflection has discussed different methodological options for the implementation of ethics discussions. For instance, the focus group participants explain that some case presentation are astounding: the accumulation of clinical details or the way clinical story is described may be bewildering. Nonetheless, they do not mention any reflection on that matter. Considering the fact that there is no "objective" presentation of a situation but always some choice to begin with in some detail, what are the arguments for selecting one or another fact among others? Some ethical committees choose to begin by a biographic presentation (and not a clinical presentation) of the situation of a person (Steinkamp and Gordijn 2003). Moreover, as ethics refers to different representations, this generates confusion. For instance, a participant of a focus group gave the example of a practice that enables health care professionals to place the patient at the centre of the care, even if he or she cannot express him/herself. This practice consists in addressing the patient, even if his or her consciousness is absent, to answer a medical question. This example provoked a debate about the classical ethical question of the "truth for the patient". In our view, this theoretical debate misses out on the point that was underlined by the participant: the way the issues are dealt with by the professional should put the patient at the centre of the care. Here, two perspectives on ethics are mixed.

Most of the factors that promote the ethical course are related to the procedures of discussion and decision. This leads to methodological problems: how can we speak with other professionals and the patient? How can we struggle against hierarchical habits? While some CECs aim to find a consensus without moral agreement about the motives of the consensus (Steinkamp and Gordijn 2003), the focus groups discussions show conversely that, in our context, a consensus cannot be reached without agreement on the arguments related to the bioethical issue at hand. The moral distress has to be appeased on the basis of a true moral agreement. The necessity of going depth about arguments, the promotion of reflexivity and debate: all this factors would be enhanced by methodological reflection. Our study underlines also the importance of an ethical course starting from the ground, as well as highlights the 
definition of the goal of CECs as a help for teams to reflect by themselves in order to find their own solution. In that context, the participants consider that everybody (as a moral subject) has the same legitimacy in participate in moral debates. Therefore inclusion, representativeness and how and where to organize that reflection would benefit methodological reflection.

According to Marcus' observations about the views of healthcare professionals toward the role of CECs in resolving clinical ethical dilemmas (2015): "facilitated communication is far more valued by health care professionals in ethics consultation along with knowledge of legal and hospital regulations rather than a particular philosophical or moral framework that can be brought to bear in resolving clinical ethical dilemmas". Our research suggests that in resolving clinical ethical dilemmas, both argumentation on the content of the issue and facilitated communication are necessary. Furthermore, participants agreed with the necessity to develop a "culture of ethics" in the hospital, in particular by means of philosophical skills that enable them to raise issues about "humanity", for instance about death. More than a set of theories, philosophy is considered as a way to enable the professional to also develop reflexivity, which in additions helps them listen to other people in their daily practice (both colleagues and patients). The analysis of the focus groups suggests that the methods used in philosophy, such as conceptual distinctions, explication of paradoxes, description of human experiences and clarification of these descriptions, as well as the justification of arguments would be helpful for the development of a "culture of ethics" in the hospital.

As mentioned by one of the interviewees and widely documented by Førde et al. (2008), the lack of transparency regarding methodology is both a brake for requesting a case consultation and a motive for reporting negative experiences of CEC consultations. Communication remains a major issue for CECs. First, it's worth reminding that there are many distinct ethical structures in France. In that context, one may understand that professionals do not know all the tools they can use. It is more surprising that a lot of them do not identify the ethical committee from their hospital as a resource. Our study suggests that health care professionals which are not involved in CECs share the representation of ethical committees as an expertise reserved to particularly difficult cases as well as the opinion that CECs are far from the "reality" of the medical team as well of the patient. The top down hospital organization may contribute to explain these representations. Jolivet (2015), in her report on ethical structures that are developing in French Ile de France Region hospitals, observed also that professionals appeal to CECs in exceptional situations. She underlines that an "everyday life ethics", or an "ethics of proximity" is also needed by health care professionals. As far as her study as well as our study suggest, communication on the existence, the purposes and methods of CECs need to be improved.

At this point, we are facing the problem that the representation of ethics as the exercise of a personal virtue does not seem to be compatible with the factors that favour ethical course, for instance collective intelligence. Does that mean that ethical reflection in CECs should be organized preferentially for health care professionals that consider ethics as the ability to conduct an analysis that encompass all pertinent points of view? Førde et al. (2008) reported time constraints and "the medical culture's lack of openness and its aversion to conflict" as major factors not to request CECs consultation (see also Hurst, 2005). The reluctance to face views and potential critique from outside and the fear to appear professionally incompetent are reasons why cases are not taken to the committee. These reluctance and fear are hardly compatible with speaking in confidence, exploring difficulties and encourage debates that we 
notice in our study as factors favouring ethical course. Moreover, as the capacity to "pass the baton" is considered positively by one participant of the focus groups, it's probably considered as a weakness for some of the physicians. Finally, according to our study, most of the doctors we interviewed consider education in humanities as useless (because of mentoring on the ward) whereas the focus group participants underline philosophy as a proper way to develop a culture of ethics in the hospital.

The representation of ethics as professional excellence may be related to the French medical context. The doctor in charge of the patient is indeed the one who, ultimately and even if there has been some space and time for collegiality, takes the decision and carries the legal responsibility for this decision. Our study suggests that to take into consideration this professional position, as a decision-maker, is essential for the comprehension of the way physicians consider CECs and use them as tools when they are dealing with difficult situations. This conception of ethics is also coherent with the widely shared opinion (among physicians) that a major ethical improvement would be the development of individual psychological support. In the interviews strong feelings of moral responsibility as well as moral distress are expressed. Doctors have to deal with a lot of difficult situations and come back home with the weight of decisions with which they are uncomfortable. However, even if this aspect of the effect of ethical reflection is not well known, CECs could be a space for reassurance. A better understanding of the situation, sharing a difficult decision, feeling free to doubt and consider that the solution must be found together: all these may get them feeling that they are reinforcing their professional virtue. Our study suggests that the moral distress caused by a difficult situation remained unresolved or was soothed depending on the ways persons enter into the relationship and were able to interact within that relationship. It seems thus necessary to take into consideration these representations of ethics, each linked to professional's postures and to work on the better way to articulate them in the context of spaces of ethical reflection.

\section{Discussion about the place of the patient in the process of dealing with an ethical problem}

Among the controversies developed in the focus groups, one was relative to the patient's role in ethical committees. CECs were created in a hospital setting with the goal of protecting patients against medical abuse and recognizing patient's rights in the decision making process (Chevrolet 2002, Mino 2002). In parallel to this evolution, nurses and other paramedical professionals claimed their right to participation in medical decision making along with doctors, given their different but essential interactions with patients. Ethical committees were thus conceived in an evolving environment in which both patients and healthcare workers demanded an increasing role along with doctors in decision making. However, as a professor in public health care we interviewed underlines: "health democracy is weak...it is the users that can help the system to evolve... we should be able to put questions of ethics before commissions composed in parity with professionals and users". In practice, patient and physician parity is far from being realized: if ethical committees today in France reflect both diversity and pluralism in their composition, the vast majority of participants are healthcare providers (principally doctors, followed by caregivers as nurse or psychologist), as well as outsiders with experience in ethical issues (philosophers, lawyers, sociologists or economists for instance). Some innovative ethical committees or ethical groups of reflection allow participation of all staff involved directly or indirectly with patients such as nurse's aides, household caregivers, and social workers. However, no patient is part of the committee. Since neither patients nor family 
members participate directly in these committees, patient representatives are the closest the patient comes to direct participation. Thus, while hospital ethics committees have partly responded to the need to provide a safe space for diverse healthcare providers to discuss ethical problems in order to better guide their practice, the patient's place at the table is still problematic.

In their study of the clinicians' evaluation of CECs in Norway, Førde et al. (2008) state that negative comments about CECs were related in particular to the lack of documentation and ignorance of "important medical and psychosocial facts in the particular case". However, the patient (or a patient representative) often bring indispensable information and perspectives into the discussion (see also Reiter-Theil 2003). Our study suggests also three ethical issues. First, it is not clear whether patients are adequately informed of these committees or their right to solicit some of them (the Clinical Ethics Centre) for advice and support. Secondly, not bringing the patient or a patient's representative physically into the deliberation may be regarded as sign of unbalance. According to our research, the actual work of ethical committees often starts from a situation of blockage between healthcare provider(s) and the patient and/or his family. While discussion participants showed a concern for the patient's implication in the process, and the need to provide a solution "for the benefit of the patient," the reason the ethical question is posed in the first place is due to the distortion between what the patient wants and what the healthcare team can or is willing to provide. When the healthcare team cannot come to a common solution, they may "appeal" to the ethics committee to help resolve the dispute. Respondents from our study said that the decision they took would have "more weight" if the decision came from an ethical committee. Thus there is a risk of using the ethical committee as an additional weapon for clinicians in the conflict between patients and their providers or between healthcare providers who have different opinions on the ethical issue at hand. Moreover, even if the decisions of ethical committees are non-binding and the main purpose is collegiality between healthcare providers, that does not mean that their decisions do not have influence or that they do not affect the patient. The cases themselves which are brought before ethical committees have serious impacts on the life of the patient and their families, especially as they are often "life or death" decisions. The weight of a decision by an ethics committee can be and is used in practice to exert influence on discussions with the patient and family members. Third, the uncertainty of the ethical decision taken permits the space for patients and their families to look for an alternative view. In some situations, the patients or families try to find another medical team who will accept his/her request. According to one respondent from our focus group "what is terrible... and horrible is that patients desperately search for an ethical committee which will take a decision in their favour and will search until they find one".

If the benefit of the patient is one of the objectives of ethical committees' work, what are the reasons which might justify the lack of involvement of patients into the ethical consultations process? One of them is related to the weight of the principle of the respect of autonomy in French medical culture. Mino (2002) explains that "American hospital ethics committees accompanied the concrete application of new judicial norms which allowed the patient to become a decision maker in his healthcare, even outside of extreme life-and-death decisions". In France, the situation is different. The principle of dignity takes indeed precedence over the principle of the respect of autonomy and the patient-physician relationship is not seen as a contract. Moreover, in France, healthcare is not a private matter. The principle of solidarity, that organizes in particular the public system of insurance, justifies the State intervention in healthcare. According to Mino "a public order of the human body is written in the Civil Law (...) The individual is usufructuary of his or her body, the State is the protector of the citizen, 
even against themselves". To a certain extent, the physician represents the State and his right of intervention in private healthcare matters.

An additional reason for the lack of direct patient involvement in ethics consultation is fear that the presence of patient and/or is family will influence the process and outcome of the ethics consultation. The ethics committee provides the opportunity for an open discussion between professionals, a "safe space" to unblock the problematic situation involving the patient and/or his or her family members or between staff members. As collegiality is seen as the main goal of these encounters, the inclusion of the patient into these encounters is seen as an intrusion into the work of healthcare professionals, who are already faced with strains in communication such as the hierarchical relationship between colleagues. According to one respondent, "we are scared that the patient will put his nose into our collegial process. We are not yet ready for that". This fear also comes from the lack of certainty in the ethical decision process. Collegiality reassures as it permits the possibility of the "weight" of a collective group decision in a process of uncertainty: the lack of epistemic authority is replaced by deontological authority. The inclusion of the patient into this process would upset the balance and the weight of the decision which is reassuring for healthcare professionals facing difficult decisions with no one right answer.

The third reason is related to the goal of ethical committee's consultations. From the focus group discussion, it was not evident if hospital ethical committees exist to reduce the suffering of healthcare providers or to reduce the suffering of patients in the face of a difficult decision. Our research in France coincides with US and UK experience which show that these discussions are primarily for the benefit of healthcare professionals themselves, rather than the patients (McLean 2007, Pederson et al. 2009, Désiré 2014). As McLean (2007) says, "it may be too simplistic to presume that ethics committees can perform a function for healthcare professionals as well as the patient. It cannot be presumed that the interests of medical professionals and patients will inevitably be the same, or that the route of an ethical decision is the same from either perspective". Susan Wolf (2006), who openly criticizes ethics committees as "clinicalled" rather than "patient-led," writes: "the proliferation of ethics committees has been part of an attempt to revolutionize medical relationships by shifting power to the patient, but is a revolution that is so far incomplete and swamped in ambivalence... it is extremely troubling that ethics committees would claim to serve the needs and interests of patients and yet exclude them from the committee room." As healthcare providers bring cases to ethical committees in which patients do not participate, both healthcare providers and ethical committees speak "for" or "for the benefit of" the patient. The patient's entry into the discussion therefore remains indirect and fragmented. While US and UK experience shows that these discussions are primarily for the benefit of healthcare professionals themselves, rather than the patients (McLean 2007), our research in France leads to a slightly more nuanced hypothesis. The advice, as well as the discussions that occur in ethical committees' sessions may create relief for teams and constitute a direct benefit for them. Nonetheless, this constitutes also a benefit for the patient whose care and well-being depends on this team. From at least this perspective, ethical committees do constitute a benefit for the patient, even if he or she is not directly involved. Moreover, the experiences of participants lead us to make some distinctions between CECs. The institutional ethical committee listens to the voice of patients, but indirectly. Most often, one or two members of the team in charge of the patient put the opinions of their patient forward. By difference, the aim of the groups of ethical reflection is explicitly focused on the team: to think together (and consequently to improve care). The ethical reflection concerns a posteriori situation, outside of any decision. Finally, the methodology of the Clinical Ethics Centre pays close attention to 
giving the same weight to all parties involved in the difficult situation. Some members of their staff meet the patient as well as his or her proxies if necessary.

Despite of these differences, the inability to reconcile the two goals of patient-led and providerled discussions remains a serious roadblock to patient participation in ethics consultation. This lack of participation questions whether institutions and healthcare professionals have confidence in the ability of the patient or his family to participate as a valuable actor in the process, or even whether they see patients as persons during the ethical debate. We remain far from a patient or relationship centred care model unless we find a way to reconcile the role of the patient and his/her family in this process.

\section{CONCLUSION}

Our study contributes to a better understanding of the French context but is not "representative" and does not allow drawing general conclusion about "French CECs". This is due to the limited number of interviews and focus groups implemented in one French Region (Auvergne-RhôneAlpes), as well as to the diversity of forms that CECs take in France. In that respect, the French context could be compared to the Norwedgian: Førde et al. (2008) who explain that committees are composed differently and function differently. Among the possible bias that we took into consideration, one was related to the strong links that exist in our region between the Faculties of philosophy and medicine. As the results show, philosophical education, method and reflexivity was considered as an important factor which favours the ethical course. On the one hand, these links are part of the explanation for putting philosophy to the forefront. On the other hand, some participants had an education in anthropology, sociology, or psychology. We may conclude cautiously that the reflexivity of philosophy helps to promote the factors favouring ethical course. We observed that the verbal interactions in the focus groups respected the professional hierarchies, in spite of the fact that the focus group was presented as a space of freedom to debate. While CECs depend on the equality between participants as moral subjects, it remains difficult to put "professional clothes" behind the door even outside professional context!

Our methodology allowed us to compare the representations and experiences of health care professionals who did and who did not had an experience of CECs. Ethics refers to professional excellence, recognition of diverse point of views and to the way these issue are dealt with by a team or a CEC. It seems to us that, in order to avoid turning a deaf ear, one may pay particular attention to the recognition of the legitimacy of everyone involved to participate to the reflection. We wish also underline this testimony: "we never learn how to speak with other professionals".

To conclude, let us underline two results. The first result is related to the lack of reflection on methodology in CECs. There is no transparent and well-established methodology for French institutional ethical committees or for groups of ethical reflection in France. However, most of the factors that favour the resolution or the smoothing of difficult situation could be enhanced by methodological reflection.

The second result is related to the patient. The fact that patients are at the heart of the professional's ethical preoccupations does not imply that they are actors in the decisions concerning them. While patients are the source of the ethical problem and the final decision 
will ultimately affect them, the justification of their actual place in the ethical consultation process remains controversial. As a respondent in our study said, the very source of the "ethical problem comes from the absence of a relationship between the healthcare provider and the patient". The lack of patient and/or family participation in the ethical course only widens this gap. 


\section{BIBLIOGRAPHY}

Baribeau, Colette. 2009. L'analyse des données des entretiens de groupe. Recherches qualitatives 18 (1): 133-148

Bertrand, Jane T., Judith E. Brown, and Victoria M. Ward. 1992. Techniques for analyzing focus group data. Evaluation Review 16: 198-209

Blanchet, Alain. 1982. Épistémologie critique de l'entretien d'enquête de style non directif. Bulletin de psychologie 26 (358): 187-194

Boitte, Pierre, Dominique Jacquemin, Thierry Vanderlinden, Olivier Nuttens, Jean-Philippe Cobbaut. 2012. De l'usage d'une grille d'éthique clinique décisionnelle à la constitution d'un lieu d'apprentissage collectif. Journal International de Bioéthique 23: 33-52

Chevrolet, Jean-Claude. 2002. Les comités locaux d'éthique clinique hospitaliers. Rev Med Suisse 2. 22451

Daubech, Lin. 2012. Le comité de bioéthique du centre hospitalier universitaire de Bordeaux. Journal International de Bioéthique 23: 69-76

Decree $n^{\circ} 83-132$ of 23 February 1983 on the Creation of a National Ethical Consultative Committee for life sciences and health. https://www.legifrance.gouv.fr/affichTexte.do?cidTexte=JORFTEXT000000687778

(Accessed 21 August 2018)

Dekeuwer, Catherine, Roland Chvetzoff, Cyril Clouzeau, Nicolas Kopp. 2011. Réflexion éthique et institutionnalisation de l'éthique. Ethique \& santé 8 (3): 125-131

Désiré, Clémence. 2014. Ethique de la recherche. Recherche en éthique. Malaises et paradoxes d'un terrain en comité d'éthique hospitalier. Journal des anthropologues https://journals.openedition.org/jda/4603. Accessed 29 August 2018

Fédération Hospitalière de France. 2016. Les comités d'éthique dans les établissements publics de santé. Internal Document

Førde, Reidun, Reidar Pederson, Victoria Akre. 2008. Clinician's evaluation of clinical ethics consultations in Norway: a qualitative study. Medicine, Health Care and Philosophy 11: 17-25

Fournier, Véronique, Marta Spranzi, Nicolas Foureur, Laurence Brunet. 2015. The "Commitment Model" for Clinical Ethics Consultations: Society's Involvement in the Solution of Individual Cases. The Journal of clinical ethics 26(4): 286-296

Fox, Ellen. 2010. Integrated Ethics: An Innovative Program to Improve Ethics Quality in Health Care. The Innovation Journal: The PublicSector Innovation Journal 15 (2): 1-36

Haute Authorité de Santé. 'Certification Manual for Healthcare Institutions 2010.' https://www.has-sante.fr/portail/upload/docs/application/pdf/2008-

12/20081217 manuel v2010 nouvelle maquette.pdf Accessed 21 August 2018

Haute Autorité de Santé. 'The Evaluation of Ethical Aspects at the HAS.' https://www.hassante.fr/portail/upload/docs/application/pdf/2013-

05/levaluation_des_aspects_ethiques_a la has.pdf. Accessed 21 August 2018

Hurst, Samia A., Sara C. Hull, Gordon DuVal, Marion Danis. 2005. How physicians face ethical difficulties: a qualitative analysis. Journal of Medical Ethics $31: 7-14$

Isambert, François-André. 1983. De la bioéthique aux comités d'éthique. Etudes 5 (358): 671683 
Jolivet, Alexia. 2015. Rapport de l'Observatoire : Étude des démarches en éthique du soin et de l'accompagnement dans les établissements de santé en Ile-de-France. http://www.espaceethique.org/ressources/\%C3\%A9tuderapport/rapport-de-lobservatoire- $\% \mathrm{C} 3 \% \mathrm{~A} 9$ tude-desd\%C3\%A9marches-en-\%C3\%A9thique-du-soin-et-de. Accessed 21 August 2018.

Kaufmann, Jean-Claude. 2007. L’entretien compréhensif. Paris : Armand Colin

Kidd, Pamela S., Mark B. Parshall. 2000. Getting the focus and the group: enhancing analytical rigor in focus group research. Qualitative Health Research 10 (3): 293-308

Law Number 88-1138 du 20 December 1988, Article L 1123-7 CSP, relative to the protection of persons in biomedical research. https://www.legifrance.gouv.fr/affichTexte.do?cidTexte=JORFTEXT000000508831.

Accessed 21 August 2018

Law Number 2002-303 du 4 mars 2002, Article 5, Relative to the rights of the sick and the quality of the healthcare system https://www.legifrance.gouv.fr/affichTexte.do?cidTexte=JORFTEXT000000227015. Accessed 21 August 2018

Law Number 2004-800 of 6th August 2004 relative to Bioethics (1). Ethics and Biomedicine. https://www.legifrance.gouv.fr/affichTexte.do?cidTexte=JORFTEXT000000441469.

Accessed 21 August 2018

Le Mintier-Feuillet, Brigitte. Les comités régionaux d'éthique en France. Réalités et perspectives. 1998. Paris: MIRE

Lilti, Thomas. Hippocrates. 2014

Magelssen, Morten, Reidar Pedersen, Reidun Førde. 2016. Novel Paths to Relevance: How Clinical Ethics Committees Promote Ethical Reflection. HEC Forum 28: 205-216

Marcus, Brian S., Gary Shank, Jestin N. Carlson, Arvind Venkat. 2015. Qualitative Analysis of Healthcare Professionals' Viewpoints on the Role of Ethics Committees and Hospitals in the Resolution of Clinical Ethical Dilemas. HEC Forum March, Volume 27, Issue 1: pp 11-34

Markova, Ivana. 2003. Les focus groups, in Serge Moscovici, Fabrice Buschini Les méthodes en sciences humaines. Paris: PUF : 220-242

McLean, Sheila. 2007. What and who are clinical ethics committees for? J Med Ethics 33(9): $497-500$

Mino, Jean-Christophe. 2002. Lorsque l'autonomie du médecin est remise en cause par l'autonomie du patient: le champ hospitalier de l'éthique clinique aux Etats-Unis et en France. Revue française des affaires sociales 2002/3: 69-102

National Consultative Committee for Ethics. http://www.ccne-ethique.fr/fr/pages/presentationdu-comite-consultatif-national-dethique-pour-les-sciences-de-la-vie-et-de-la. Accessed 21 August 2018

Pederson, Reidar, Victoria Akre, Reidun Førde. 2009. Barriers and challenges in clinical ethics consultations: the experiences of nine clinical ethics committees. Bioethics 23 (8): 460-469

Rasoal, Dara, Kirsti Skovdahl, Mervyn Gifford, and Annica Kihlgren. 2017. Clinical Ethics Support for Healthcare Personnel: An Integrative Literature Review. HEC Forum 29: 314-315

Reiter-Theil, Steila. 2003. Balancing the perspectives. The patient's role in clinical ethics consultation. Medicine, Health Care and Philosophy 6: 247-254 
Steinkamp, Norbert, and Bert Gordijn. 2003. Ethical case deliberation on the ward. A comparison of four methods. Medicine, Health Care and Philosophy 6: 235-246

Wolf, Susan. 2006. Ethics Committees and Due Process: Nesting Rights in a Community of Caring. Maryland Law Review 50 (3): 805-811 